Article

\title{
Kinetic Modeling of Dihydroxyacetone Production from Glycerol by Gluconobacter oxydans ATCC 621 Resting Cells: Effect of Fluid Dynamics Conditions
}

\author{
Susana de la Morena, Mateusz Wojtusik $(0$, Victoria E. Santos * $*$ and Felix Garcia-Ochoa \\ Chemical Engineering and Materials Department, Universidad Complutense de Madrid, 28040 Madrid, Spain; \\ smlopez@quim.ucm.es (S.d.1.M.); mwojtusik@ucm.es (M.W.); fgochoa@ucm.es (F.G.-O.) \\ * Correspondence: vesantos@ucm.es; Tel.: +34-913944179
}

Received: 14 October 2019; Accepted: 7 January 2020; Published: 10 January 2020

check for updates

\begin{abstract}
Dihydroxyacetone production from glycerol has been studied. Cultures of Gluconobacter oxydans ATCC 621, a promising microorganism that is able to convert glycerol into dihydroxyacetone, has been employed. In this work, the influence of oxygen transport rate and the fluid dynamic conditions have been studied working with resting cells cultures. Several experiments were carried out at two different scales: $250 \mathrm{~mL}$ Erlenmeyer flasks and a $2 \mathrm{~L}$ stirred tank bioreactor, varying the agitation speed. Product and substrate concentration were determined employing high-performance liquid chromatography. Additionally, oxygen concentration was measured in the runs carried out in stirred tank reactors. Taking into account the results obtained in these experiments, three different behaviors were observed, depending on the mass transfer and chemical reactions rates. For experiments with low stirring speed (below $200 \mathrm{rpm}$ for shake flasks and $300 \mathrm{rpm}$ for reactors), the oxygen transport rate is the controlling step, while at high stirring speed (over $300 \mathrm{rpm}$ in shake flasks and $560 \mathrm{rpm}$ in the bioreactor), the chemical reaction is controlling the overall process rate. In some runs conducted at medium agitation, a mix control was found. All the kinetic models were able to reproduce experimental data and fulfill thermodynamic and statistical criteria, highlighting the importance of the mass transfer rate upon this system.
\end{abstract}

Keywords: dihydroxyacetone; kinetic modelling; oxygen transfer rate; glycerol valorization; Gluconobacter oxydans

\section{Introduction}

Glycerol has become a waste due to the enormous availability caused by the huge growth of the biodiesel production industry [1], which produces glycerol as a by-product; approximately $10 \mathrm{~kg}$ of glycerol are produced per $100 \mathrm{~kg}$ of biodiesel [2]. An estimation of OECD-FAO (Organization for Economic Co-operation and Development-Food and Agricultural Organization) assumes that the global production of biodiesel will grow 4.5\% annually, reaching $41 \mathrm{Mm} 3$ in 2022 [2]. This makes the development of different sustainable processes that are able to transform the growing amount of glycerol produced into valuable products peremptory.

Glycerol has been employed in many industries (food, pharmaceutical, cosmetic, chemical, etc.), due to its versatile physicochemical properties [3]. Amongst all these applications, one promising route is the bioconversion of glycerol into chemical products and precursors, such as 1,3-dihydroxyacetone (DHA). DHA is extensively used in the cosmetic industry due to its employment as a building block for the production of various fine chemicals such as 1,3-propanediol and citric acid (being an intermediate compound in this processes) [4], with microbial production being the preferred synthesis pathway, in contrast with the chemical processes, which have expensive safety requirements [5]. 
The most widely employed microorganism to produce DHA from glycerol as raw material is Gluconobacter oxydans, although there are several different works using other microorganisms [5-16]. G. oxydans is a Gram-negative aerobic bacterium, whose respiratory metabolism allows it to partially oxidize different organic compounds [17]. The enzyme that transforms glycerol into DHA, glycerol dehydrogenase (corresponding to the classification EC 1.1.1.6), is located in the microorganism membrane [18], and has been employed as a separate catalyst in immobilized configurations to produce DHA $[19,20]$. This provides $G$. oxydans with the ability to transform glycerol into DHA rapidly and efficiently. However, as the whole process is intimately associated to the oxygen caption, and this compound is the final donor of electrons in this process, it is crucial to evaluate the influence of oxygen transport from air to the culture media and to the membrane of the microorganism [16].

In the literature, there have been some efforts to establish a valid kinetic model to describe the transformation of glycerol into DHA. In 2003, Hekmat et al. [5] employed a semi-continuous stirred tank bioreactor combined with a column with irregular packing, in which the microorganism was immobilized, in order to minimize operational costs such as cleaning, sterilization, or inoculation. In order to fix the optimal operating conditions, the authors evaluated several kinetic parameters for semi-continuous systems, describing the rate of growth by means of a double substrate limitation Monod model, coupled with a linear product inhibition. Although the experimental approach improved final DHA yield and productivity, the kinetic model was not able to explain some phenomena associated to this process, and the kinetic model employed was purely empirical [5].

Ma et al., in 2009, took a different approach in order to describe DHA production, using a modified Aiba model for cell growth and the Leudeking-Piret growth associate model for the product formation description [21]; in this case, the inhibitory effect of both DHA and glycerol presence on biomass growth and therefore DHA production were considered. Additionally, Ma et al. compared two different G. oxydans strains: the wild type and a genetically modified strain using He-Ne laser irradiation technology [21]. The kinetic model proposed was able to describe correctly the experimental results achieved, both for the natural and for the modified strains.

Other authors also describe a strong substrate and product inhibition on DHA production [12,13,15,22]. Furthermore, Dikshit et al. employed various different kinetic models in order to describe DHA production considering the effect of substrate inhibition [23] and substrate and product combined inhibition [24]. In this work, an immobilized G. oxydans in reticulated polyurethane was used, studying the effect of raw glycerol over the kinetic parameters and both substrate and product inhibitions [23,24].

However, none of the previously described kinetic models consider the oxygen availability. The importance of oxygen transfer rate in aerobic the bioprocess has already been pointed out in many works [16,25-28]. Recently, several authors have put their effort on describing the influence of oxygen transfer rate on DHA production. Zheng et al. compared several different kinetic parameters for three different values of the oxygen volumetric mass transfer coefficient $\left(k_{L} a\right)$, using crude glycerol as the carbon source and employing Gluconobacter frateurii CGMCC 5397 as the biocatalyst [8]. The results shown in this work demonstrate that an increment on mass transfer rate by improving $\mathrm{k}_{\mathrm{L}}$ a leads to an increase of both biomass growth and DHA production rates [8]. Poljungreed et al. studied the effect of the amount of dissolved oxygen on DHA final concentration and yield in a $7 \mathrm{~L}$ stirred tank bioreactor (STBR) using G. frateurii BCC 36199 strain cultured in glycerol and inorganic salts medium. The results shown an improvement in both factors-final concentration and yield—which was directly related with the amount of available oxygen [11].

Regarding the strain employed in this work, previously published results [16] have shown that there is a need to establish a minimum oxygen transfer rate in order to ensure the highest culture activity. Thus, we can avoid the decrease of DHA production rate due to the oxygen transfer rate (OTR) limitation and its control over the overall process rate [16].

The aim of this work is to establish a kinetic model that is able to correlate OTR with DHA production in two different scales: low-scale $250 \mathrm{~mL}$ flasks and medium-scale $2 \mathrm{~L}$ STBR. In order to achieve this objective, several experiments were carried out both in Erlenmeyer flasks and STBR, 
varying the agitation speed. Operating conditions were fixed, taking into account the results achieved in previous works $[15,16]$. Throughout the study, resting cells were employed in operation mode. With this kinetic model, it will be possible to establish a clear dependence between OTR and DHA productivity, highlighting even more the importance of the mass transfer phenomenon in this process. Mass transfer rate has not been considered in previous works studying this bioprocess. Moreover, the improvement of OTR would lead to an increase in the DHA productivity and in the overall feasibility of the process.

\section{Results}

The experiments realized in this work are shown in Table 1. Based on the results obtained in the aforementioned runs, three different kinetic modeling approaches have been used in order to describe DHA concentration evolution alongside each experiment, considering the different behaviors observed in each case. In all runs, as it was observed in a previous work [16], the glyceric acid (a by-product) concentration was negligible; therefore, this acid was not considered in order to develop the kinetic models in this work.

Table 1. Experimental planning: runs carried out under different operating conditions (biomass concentration and agitation) employing both shake flasks (runs 1 to 18) and stirred tank bioreactor (STBR) (runs 19 to 24).

\begin{tabular}{|c|c|c|c|}
\hline Run & $C_{X}{ }^{1}\left(g \cdot L^{-1}\right)$ & $\mathrm{N}^{2}(\mathrm{rpm})$ & Experimental Device \\
\hline 1 & 0.1 & \multirow{6}{*}{100} & \multirow{18}{*}{ Shake flasks } \\
\hline 2 & 0.2 & & \\
\hline 3 & 0.3 & & \\
\hline 4 & 0.4 & & \\
\hline 5 & 0.5 & & \\
\hline 6 & 1.0 & & \\
\hline 7 & 0.2 & & \\
\hline 8 & 0.3 & & \\
\hline 9 & 0.4 & 200 & \\
\hline 10 & 0.5 & & \\
\hline 11 & 1.0 & & \\
\hline 12 & 0.3 & \multirow{4}{*}{300} & \\
\hline 13 & 0.4 & & \\
\hline 14 & 0.5 & & \\
\hline 15 & 1.0 & & \\
\hline 16 & 0.4 & \multirow{3}{*}{400} & \\
\hline 17 & 0.5 & & \\
\hline 18 & 1.0 & & \\
\hline 19 & \multirow{5}{*}{0.5} & 300 & \multirow{5}{*}{ STBR (Stirred tank bioreactor) } \\
\hline 20 & & 360 & \\
\hline 21 & & 420 & \\
\hline 22 & & 560 & \\
\hline 23 & & 650 & \\
\hline
\end{tabular}

\subsection{Shake Flask Experiments}

Figures 1-4 show the evolution of both substrate (glycerol) and product (DHA) concentrations for the different experiments carried out at low-scale (shake flasks). A clear linear tendency with time for DHA production as well as for glycerol consumption can be observed in these figures, at least at short times. However, only at the lowest agitation (100 rpm), this linear tendency is maintained throughout the run; while in the rest of the runs, the linear trend is only observed at shorter times. Furthermore, it is important to note that at the lowest agitation speed, both evolutions-glycerol and DHA concentrations-are independent of the biomass concentration employed, which is a clear sign of the existence of a mass transfer limitation phenomenon affecting the DHA production rate. 
Finally, it is necessary to point out that the glycerol is totally consumed during the experimental time in all of the runs carried out in this work.
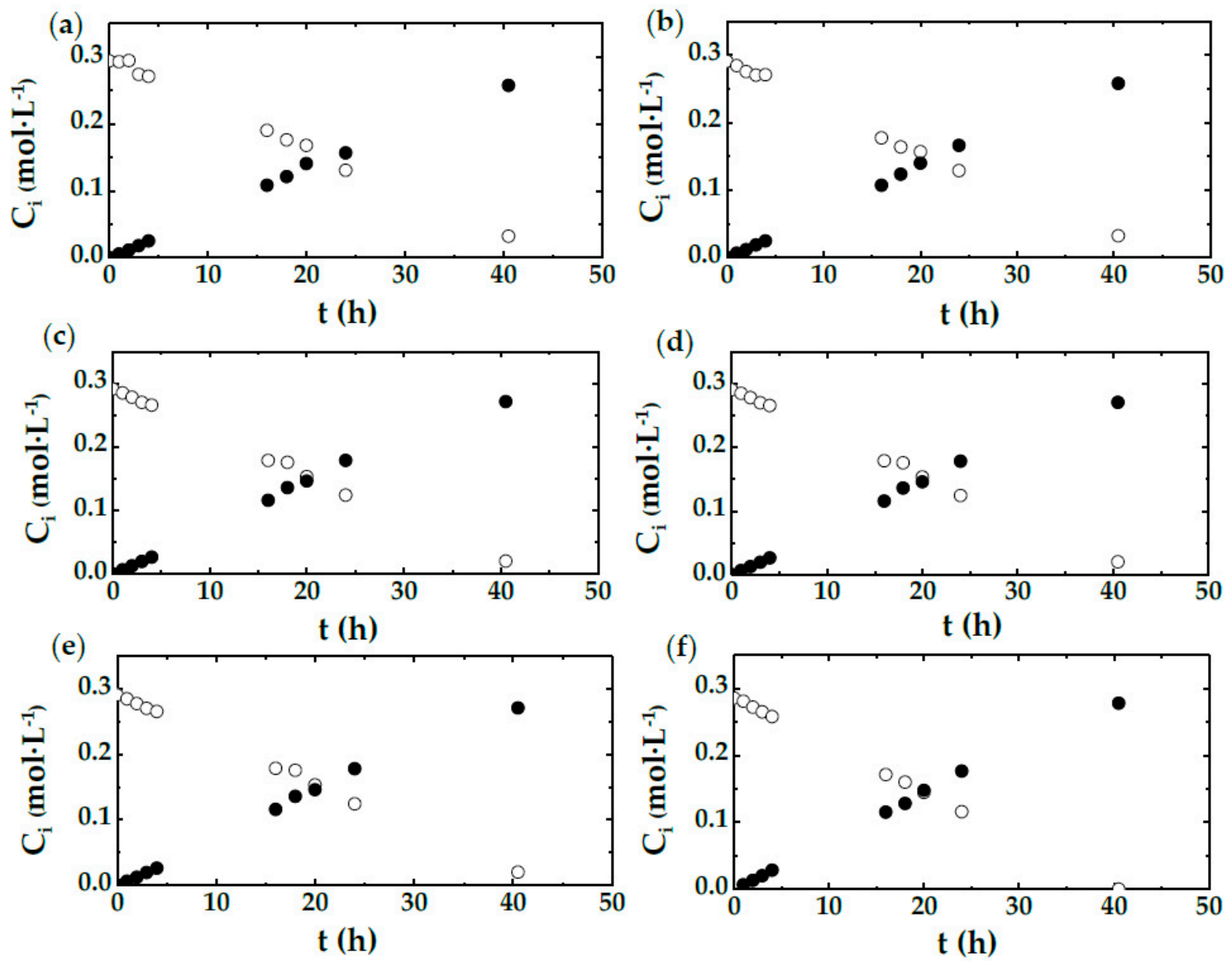

Figure 1. Experimental results. 1,3-dihydroxyacetone (DHA) $(\bullet)$ and glycerol $(\bigcirc)$ concentrations vs. time for runs 1 to 6 (see Table 1) carried out in shake flasks. All runs conducted at agitation speed of $100 \mathrm{rpm}$ employing different biomass concentrations according to (a) 0.1 , (b) 0.2 , (c) 0.3 , (d) 0.4 , (e) 0.5 , and (f) $1.0 \mathrm{~g} \cdot \mathrm{L}^{-1}$.

On the other hand, as can be seen in Figures 2-4, the linear tendency commented does not last during the entirety of the experiments represented in these figures. Although the linear phase is the same for each of the stirring speeds over all the runs, both the slope and duration of this phase vary with agitation speed. Thus, stirring speed—and therefore, mass transfer rate-had an important impact on DHA production rate for the runs shown in Figures 2-4.

This effect can also be stated over the specific productivity values $\left(\mathrm{P}_{X}\right)$, which are shown in Figure 5. In this figure, it can be appreciated that the effect of the stirring speed is more impactful over $\mathrm{P}_{\mathrm{X}}$ for the amount of biomass employed in each case, which is in line with the observation previously described for the experimental results. In addition, these results are comparable to the work present in the literature. Jackson et al. reached a $P_{X}$ of $3.21 \times 10^{-2} \mathrm{~mol} \cdot \mathrm{gX}^{-1} \cdot \mathrm{h}^{-1}$ employing an $\mathrm{N}$ of $180 \mathrm{rpm}$ and a biomass concentration of $0.66 \mathrm{gx}_{\mathrm{X}} \cdot \mathrm{L}^{-1}$ using commercial glycerol and G. oxydans resting cells [29], whereas in this work, we have reached a value of $2.25 \times 10^{-2} \mathrm{~mol} \cdot \mathrm{gX}^{-1} \cdot \mathrm{h}^{-1}$ for similar conditions. However, as can be seen in Figure 5, this productivity can be increased substantially through incrementing stirring rate and, therefore, favoring OTR. 
(a)

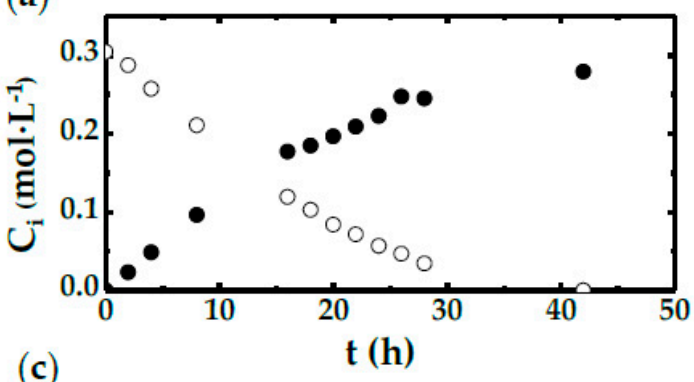

(c)

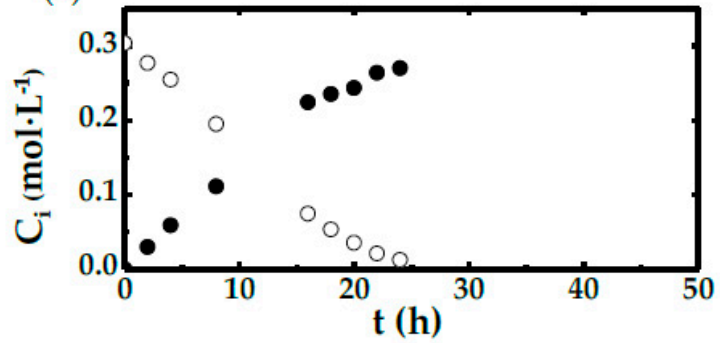

(b)
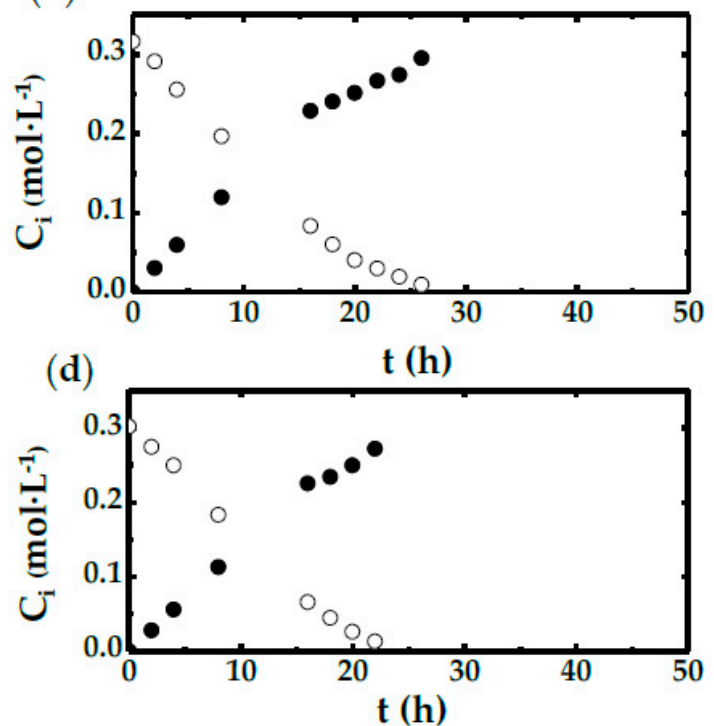

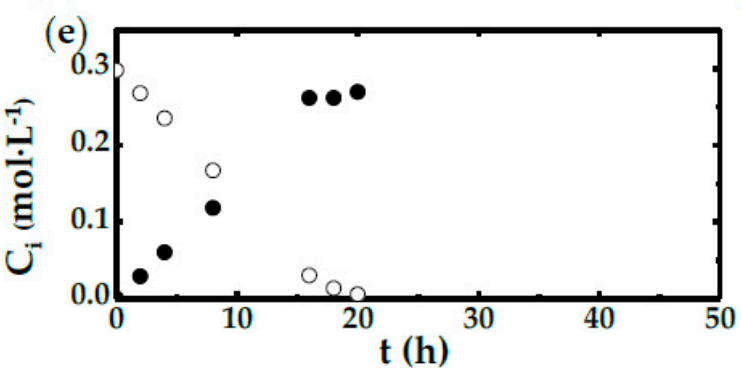

Figure 2. Experimental results. DHA $(\bullet)$ and glycerol $(\bigcirc)$ concentrations vs. time for runs 7 to 11 (see Table 1) carried out in shake flasks. All runs conducted at agitation speed of $200 \mathrm{rpm}$ employing different biomass concentrations according to (a) 0.2 , (b) 0.3 , (c) 0.4 , (d) 0.5 , and (e) $1.0 \mathrm{~g} \cdot \mathrm{L}^{-1}$.
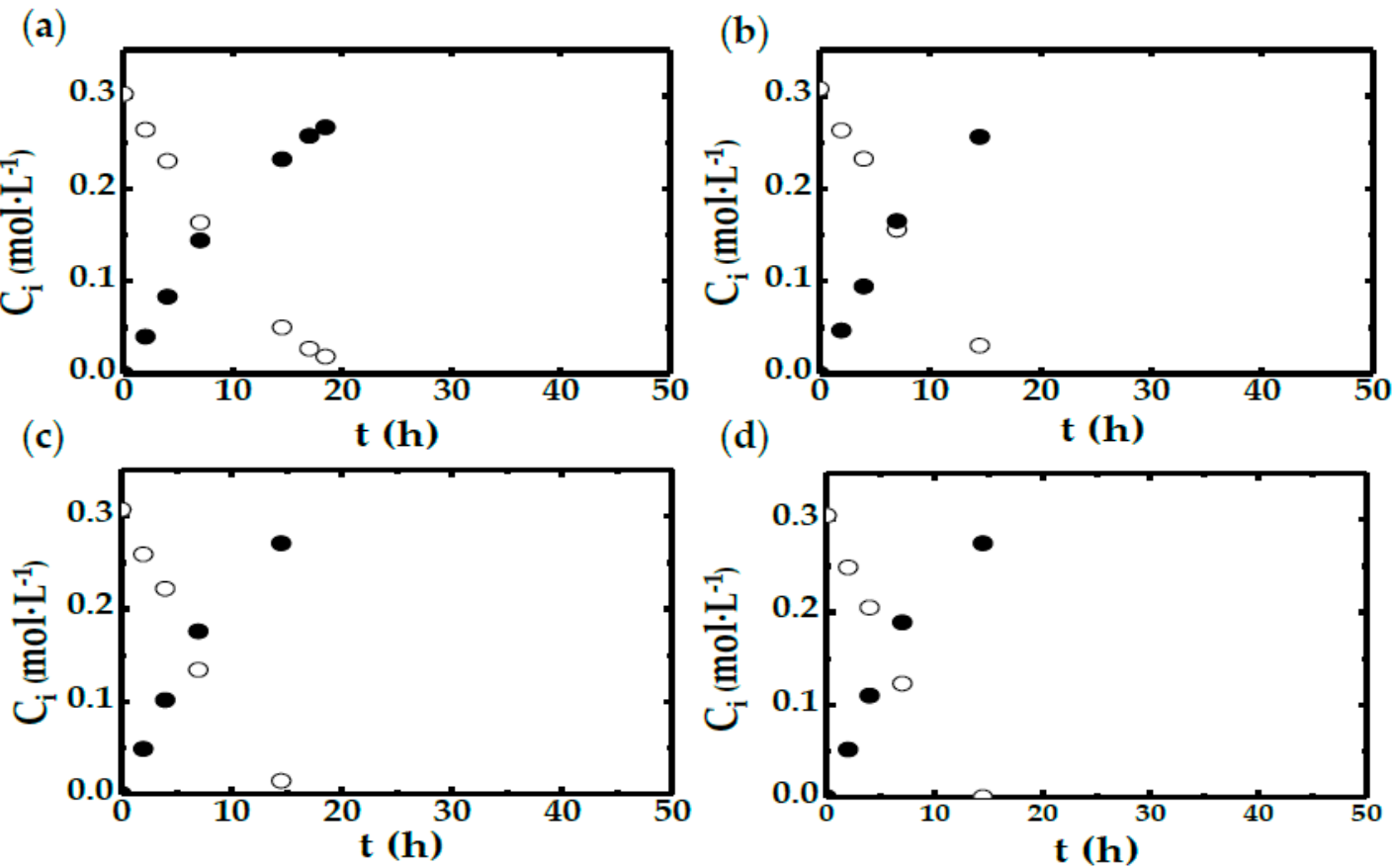

Figure 3. Experimental results. DHA $(\bullet)$ and glycerol $(\bigcirc)$ concentrations vs. time for runs 12 to 16 (see Table 1) carried out in shake flasks. All runs conducted at agitation speed of $300 \mathrm{rpm}$ employing different biomass concentrations according to (a) 0.3 , (b) 0.4 , (c) 0.5 , and (d) $1.0 \mathrm{~g} \cdot \mathrm{L}^{-1}$. 
(a)

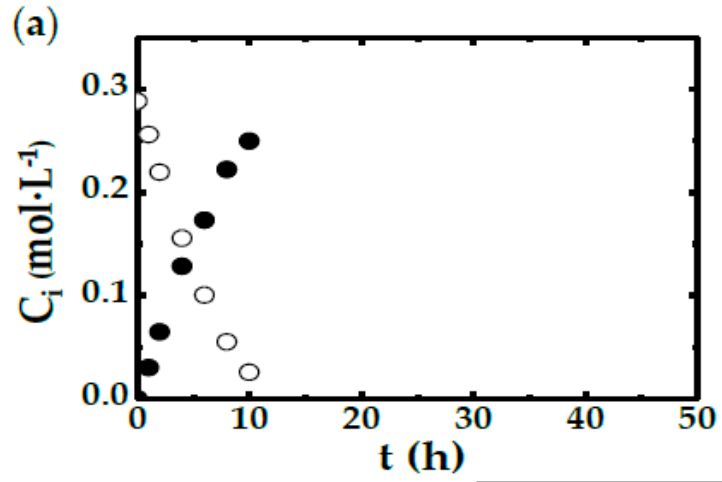

(b)

(c)

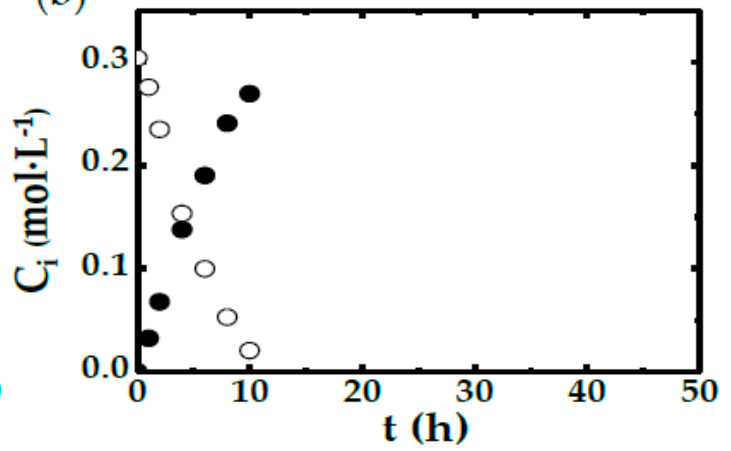

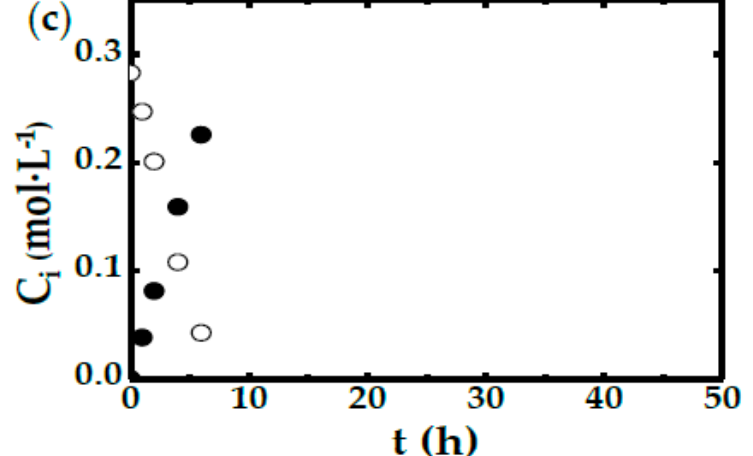

Figure 4. Experimental results. DHA $(\bullet)$ and glycerol $(\bigcirc)$ concentrations vs. time for runs 17 to 19 (see Table 1) carried out in shake flasks. All runs conducted at agitation speed of $300 \mathrm{rpm}$ employing different biomass concentrations according to (a) 0.4 , (b) 0.5 , and (c) $1.0 \mathrm{~g} \cdot \mathrm{L}^{-1}$.

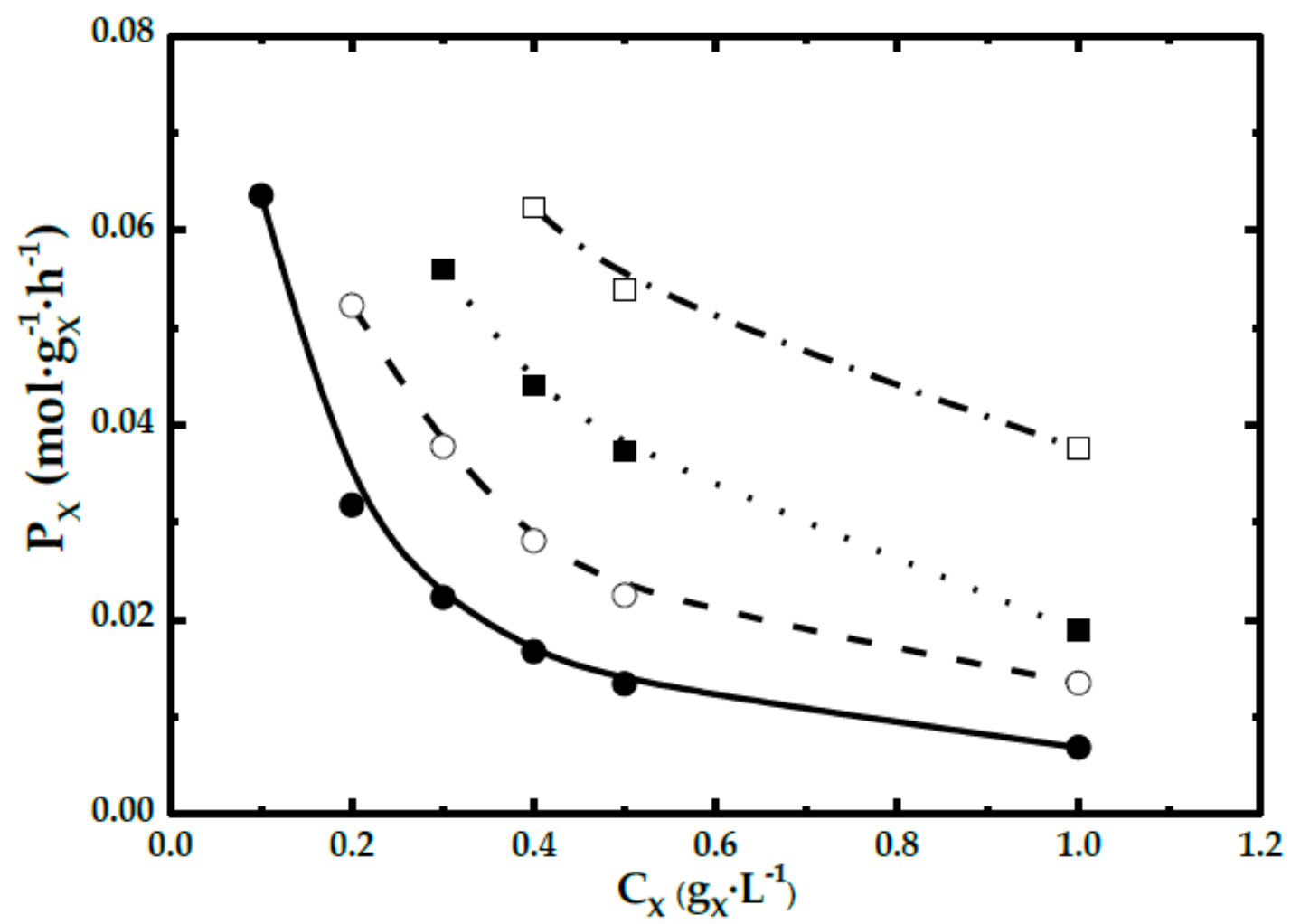

Figure 5. Productivity results corresponding to each biomass concentration employed for shake flask runs: $100 \mathrm{rpm}(\bullet), 200 \mathrm{rpm}(\bigcirc), 300 \mathrm{rpm}(\boldsymbol{\bullet})$, and $400 \mathrm{rpm}(\square)$. 


\subsection{STBR Experiments}

The results of the runs performed at STBR scale are given in Figure 6. As can be seen, both glycerol and DHA concentrations change with the stirring speed employed in each run. For the lowest agitation (300 rpm), both glycerol and DHA concentration maintained a linear time course trend.

(a)

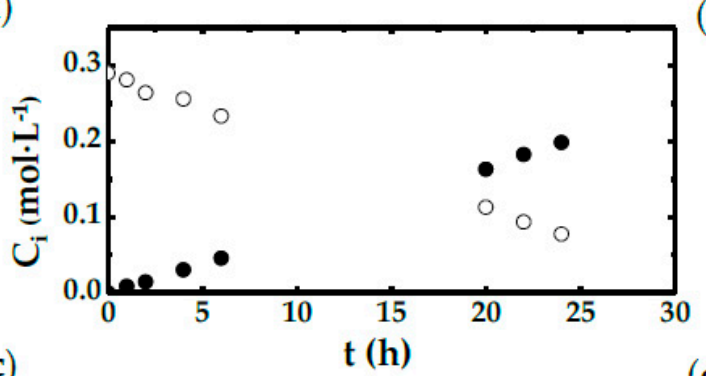

(c)

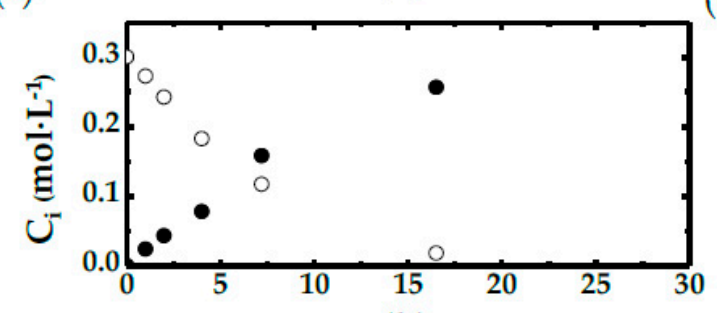

(e)

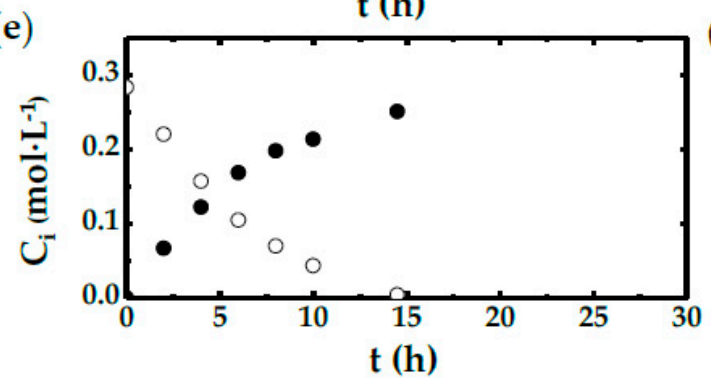

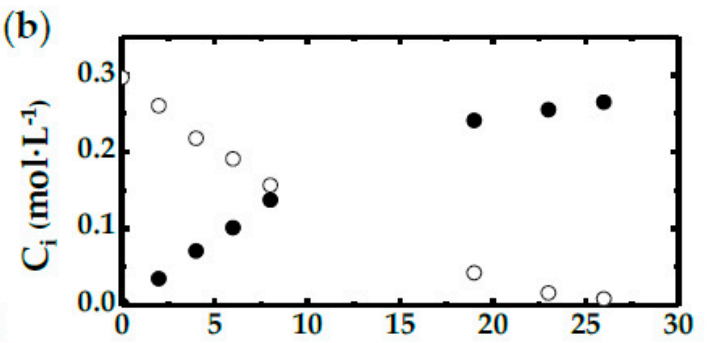

(d)
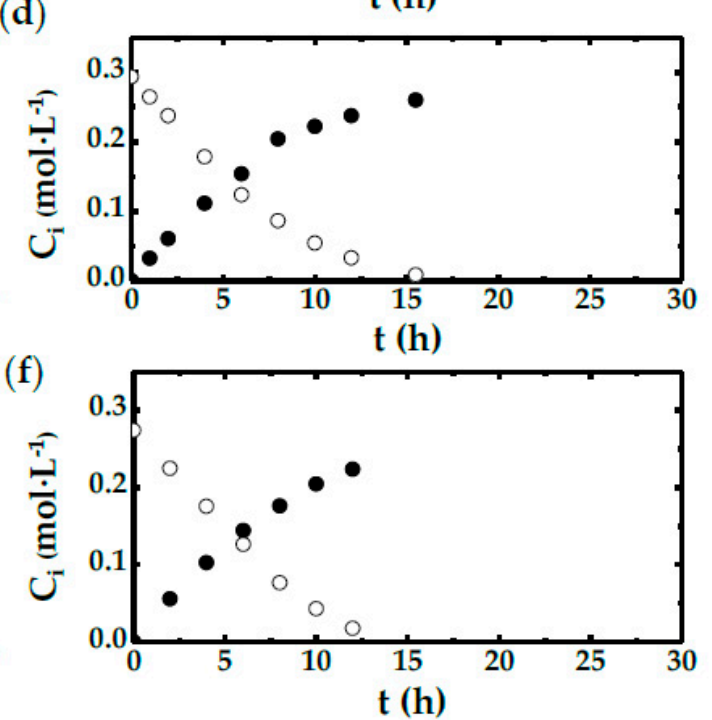

Figure 6. Experimental results. DHA $(\bullet)$ and glycerol $(\bigcirc)$ concentrations vs. time for runs 20 to 24 (see Table 1 carried out in a stirred tank bioreactor (STBR). All runs conducted with a biomass concentration of $0.5 \mathrm{~g} \cdot \mathrm{L}^{-1}$, employing several stirring speeds according to: (a) 300, (b) 360, (c) 420, (d) 560, (e) 650, and (f) $750 \mathrm{rpm}$.

However, as stirring increases, the evolutions of both compound concentrations change into hyperbolic type, in which the first part of the time-course evolution for both concentrations resembles a linear evolution with a higher slope than the first experiment at $300 \mathrm{rpm}$, and it is the same tendency observed in the runs carried out in shake flasks.

For the runs with higher agitation, DHA evolution is the same, which is maintained despite the stirring speed increase. It is important to point out that for all the experiments shown in Figure 6, the biomass concentration employed remains the same $\left(0.5 \mathrm{~g} \cdot \mathrm{L}^{-1}\right)$.

As with the experiments carried out in shake flasks, $\mathrm{P}_{\mathrm{X}}$ was evaluated for each run, and the results are shown in Table 2. As can be seen in this table, the productivity reached for these experiments is lower than that obtained in flask experiments. However, it is clear that the same tendency can be observed in both cases, as the productivity increases with the stirring rate. 
Table 2. Productivity results achieved in STBR runs.

\begin{tabular}{cc}
\hline $\mathbf{N}$ & $\mathbf{P}_{\mathbf{X}}\left(\mathbf{m o l} \cdot \mathbf{g}_{\mathbf{x}}{ }^{\mathbf{1}} \cdot \mathbf{L}^{-\mathbf{1}}\right) \cdot \mathbf{1 0}^{\mathbf{2}}$ \\
\hline 300 & 1.65 \\
360 & 2.03 \\
420 & 3.11 \\
560 & 3.34 \\
650 & 3.46 \\
750 & 3.73 \\
\hline
\end{tabular}

\section{Discussion}

The results observed in both of the experimental devices employed leads to the following considerations, which have to be addressed in order to formulate an adequate kinetic model to describe DHA production:

- There are three different observed patterns, which depend on the stirring speed employed. This is valid for both shake flasks and STBR.

- For low agitation, DHA production is strongly related to the stirring speed and, therefore, to the mass transfer rate.

- For high stirring speeds, biomass concentration exerts a strong influence on DHA evolution. When the amount of biocatalyst is maintained, DHA evolution is not affected by agitation speed. Thus, the production rate of DHA depends on the chemical reaction rate.

- There is a mixed behavior when the agitation takes a medium value; in this case, the process rate seems to depend on the oxygen availability, or the OTR from gas to the culture media, which is directly related to the stirring speed.

Taking into account these factors, several different kinetic models were proposed to describe each one of the situations described above.

\subsection{Kinetic Model for Low Agitation: Mass Transfer Rate Evaluation}

OTR can be evaluated by means of the oxygen mass balance $[27,28]$, according to Equation (1):

$$
\mathrm{OTR}=\mathrm{k}_{\mathrm{L}} \mathrm{a} \cdot\left(\mathrm{C}_{\mathrm{O} 2}^{*}-\mathrm{C}_{\mathrm{O} 2}\right)
$$

where $\mathrm{C}_{\mathrm{O} 2}$ is the oxygen concentration in the liquid phase $\left(\mathrm{mol} \cdot \mathrm{L}^{-1}\right)$ and $\mathrm{C}_{\mathrm{O} 2}^{*}$ is the saturation oxygen concentration $\left(\mathrm{mol} \cdot \mathrm{L}^{-1}\right)$.

For the experiments carried out at low agitation, it can be assumed that the concentration of dissolved oxygen (DO) will be very low or negligible due to the slower income of oxygen compared to the oxygen consumption by the culture. Therefore, the DHA production rate will be strongly related to OTR. Therefore, the DHA production rate can be described by Equation (2):

$$
\frac{\mathrm{dC}_{\mathrm{DHA}}}{\mathrm{dt}}=\mathrm{k}_{\mathrm{L}} \mathrm{a} \cdot \mathrm{C}_{\mathrm{O} 2}^{*}
$$

where $\mathrm{C}_{\mathrm{DHA}}$ is DHA concentration $\left(\mathrm{mol} \cdot \mathrm{L}^{-1}\right)$ and $\mathrm{k}_{\mathrm{L}}$ a is the volumetric mass transfer coefficient $\left(\mathrm{h}^{-1}\right)$.

As predicted by Equation (2), a linear evolution of $\mathrm{C}_{\mathrm{DHA}}$ with time is expected. Thus, integrating Equation (2), assuming an initial DHA concentration $=0$, Equation (3) is obtained:

$$
\mathrm{C}_{\mathrm{DHA}}=\mathrm{k}_{\mathrm{L}} \mathrm{a} \cdot \mathrm{C}_{\mathrm{O} 2}^{*} \cdot \mathrm{t},
$$

where $\mathrm{t}$ is time $(\mathrm{h})$.

This tendency can be observed in two different ways in the experiments carried out in this work: 
- For low agitation rate, the linear trend of DHA concentration with time adjusts to the tendency shown in Equation (3).

- For the rest of experiments, only the first stage, at short times, DHA concentration evolves following a linear relationship with time.

Thus, Equation (2) can be used to describe the DHA production rate for the cases in which this linear tendency is observed throughout the whole process, which is evident in runs 1 to 6 (in shake flasks, at $100 \mathrm{rpm}$ stirring speed) and 19 (in STBR, at $300 \mathrm{rpm}$ stirring speed).

In Figure 6, the experimental results of these experiments are represented versus the results achieved using Equation (3) in both cases. The kinetic and statistical parameters values are given in Table 3.

Table 3. Kinetic and statistical parameters calculated for low agitation experiments with mass transfer control of the overall process rate. Runs 1 to 6 (shake flasks) and 19 (STBR).

\begin{tabular}{ccccc}
\hline Run & $\mathbf{C}_{\mathbf{X}}\left(\mathbf{g} \cdot \mathbf{L}^{-\mathbf{1}}\right)$ & $\mathbf{C}_{\mathbf{O} 2}^{*}\left(\mathbf{m o l} \cdot \mathbf{L}-{ }^{1}\right) \cdot 10^{4}$ & $\mathbf{k}_{\mathbf{L}} \mathbf{a} \cdot \mathbf{1 0} \mathbf{3}^{\mathbf{3}} \cdot\left(\mathbf{h}^{-\mathbf{1}}\right)$ & $\mathbf{r}^{\mathbf{2}}$ \\
\hline 1 & 0.1 & & & \\
2 & 0.2 & & & \\
3 & 0.3 & 4.75 & $6.92 \pm 0.05$ & 0.997 \\
4 & 0.4 & & & \\
5 & 0.5 & & & \\
6 & 1.0 & 4.75 & $8.21 \pm 0.05$ & 0.9997 \\
\hline 19 & 0.5 & & & \\
\hline
\end{tabular}

As can be seen in Figure 7, the kinetic model (Equation (3)) is able to reproduce the experimental results of all the runs carried out at low agitation speeds in a suitable way. The results presented in Table 3 show a very small deviation of the kinetic parameter, $\mathrm{k}_{\mathrm{L}} \mathrm{a}$, and a value of $\mathrm{r}^{2}$ very close to 1 . Furthermore, as can be seen in Figure 7a, the biomass concentration does not exert any influence on DHA production rate. Hence, it is possible to say that for this stirring speed, the mass transfer rate is controlling the overall process rate.

On the other hand, it is possible to estimate the value of $\mathrm{k}_{\mathrm{L}}$ a for the rest of experiments. However, it is necessary to employ only the initial linear stage, since the DHA concentration time evolves with time from a linear to a hyperbolic trend, as has been shown in Figures 2-4 and Figure 6.

The results achieved for $\mathrm{k}_{\mathrm{L}}$ a calculation are presented in Table 4 . With the results shown in this table, $\mathrm{k}_{\mathrm{L}}$ a values were fitted to agitation speed in order to correlate the stirring speed with the mass transfer rate. These correlations are given by Equations (4) and (5).

$$
\begin{gathered}
\left(\mathrm{k}_{\mathrm{L}} \mathrm{a}\right)_{\text {Flask }}=10^{-4.75} \cdot \mathrm{N}^{1.2} \mathrm{r}^{2}=0.997 \\
\left(\mathrm{k}_{\mathrm{L}} \mathrm{a}\right)_{\mathrm{STBR}}=10^{-4.90} \cdot \mathrm{N}^{1.1} \quad \mathrm{r}^{2}=0.984
\end{gathered}
$$

Table 4. Mass transfer coefficient values calculated for runs 7 to 18 (shake flasks) and runs 20 to 24

\begin{tabular}{|c|c|c|c|c|c|c|c|c|}
\hline Run & \multicolumn{2}{|c|}{$\mathrm{k}_{\mathrm{L}} \mathrm{a} \cdot 10^{3} \cdot\left(\mathrm{h}^{-1}\right) \mathrm{N}(\mathrm{rpm})$} & Run & \multicolumn{2}{|c|}{$\mathrm{k}_{\mathrm{L}} \mathrm{a} \cdot 10^{3} \cdot\left(\mathrm{h}^{-1}\right) \mathrm{N}(\mathrm{rpm})$} & \multirow{2}{*}{$\begin{array}{c}\text { Run } \\
20\end{array}$} & \multirow{2}{*}{$\begin{array}{l}\mathbf{k}_{\mathbf{L}} \mathbf{a} \cdot \mathbf{1 0} \mathbf{0}^{\mathbf{3}} \cdot\left(\mathbf{h}^{-\mathbf{1}}\right) \\
10.0 \pm 0.7\end{array}$} & \multirow{2}{*}{$\frac{\text { N (rpm) }}{360}$} \\
\hline 7 & & & 13 & & & & & \\
\hline 8 & & & 14 & $14.6 \pm 0.7$ & 300 & 21 & $12.5 \pm 0.3$ & 420 \\
\hline 9 & $8.2 \pm 0.4$ & 200 & 15 & & & 22 & $17.7 \pm 0.5$ & 560 \\
\hline 10 & & & 16 & & & 23 & $19.6 \pm 0.6$ & 650 \\
\hline 11 & & & 17 & $19.9 \pm 0.5$ & 400 & 24 & $23.6 \pm 0.5$ & 750 \\
\hline 12 & $14.6 \pm 0.7$ & 300 & 18 & & & & & \\
\hline
\end{tabular}
(STBR); all runs conducted at low agitation. 

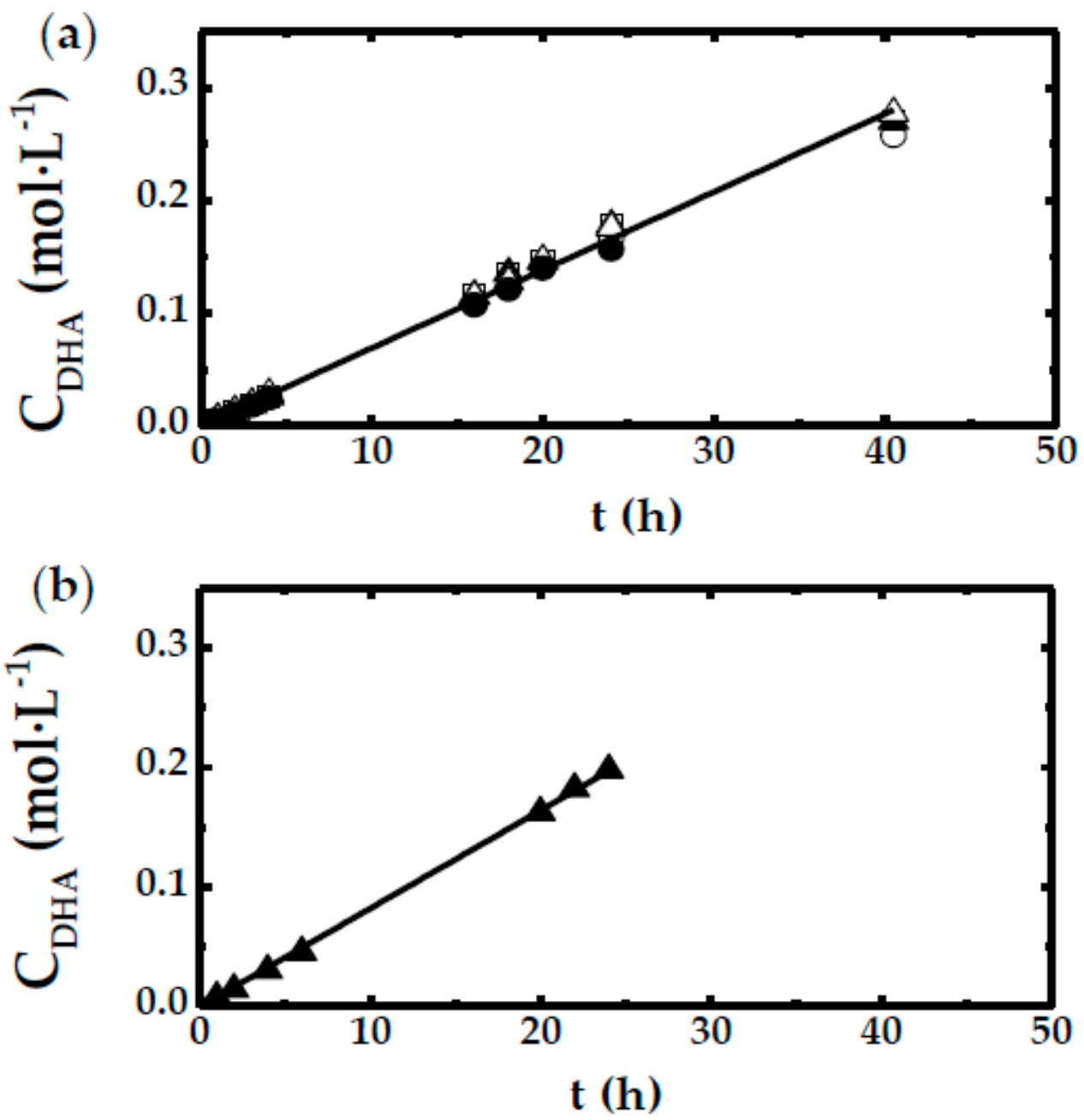

Figure 7. Reproduction of DHA concentration vs. time for (a) runs 1 to 6 (carried out in shake flasks) and (b) for run 19 (carried out in STBR), the agitation being (a) $100 \mathrm{rpm}$ (flasks) and (b) $300 \mathrm{rpm}$ (STBR). Different biomass concentrations were employed according to the following legends: $0.1(\bullet)$, $0.2(\bigcirc), 0.3(\square), 0.4(\square), 0.5(\mathbf{\Delta})$, and $1.0 \mathrm{~g} \cdot \mathrm{L}^{-1}(\Delta)$. Points corresponding to experimental results, lines corresponding to kinetic model simulation when the oxygen transport rate (OTR) is controlling the overall process rate. Model Equations (2) and (3).

As can be seen in Table 4, all of the calculated $\mathrm{k}_{\mathrm{L}}$ a values are directly related to the agitation speed. Furthermore, as given by Equations (4) and (5), these relationships are similar in both systems, the effect of stirring speed depending on a function that is almost linear in both cases. While Equation (4) is a reasonable relationship [16,30], Equation (5) is not, which is surely due to the $\mathrm{k}_{\mathrm{L}}$ a values having been calculated under conditions where mass transfer is not the limiting step; thus, these values are not realistic [16]. Therefore, this method is useful to evaluate the impact of the mass transfer rate over the DHA production rate in a rapid and simple way.

\subsection{Kinetic Model for High Agitation: Chemical Reaction Rate Calculation}

As the reaction of the transformation of glycerol into DHA is carried out by a membrane-embedded enzyme [18], it can be described by a Michaelis-Menten-type kinetic model. Accordingly, DHA production model is stated by Equation (6):

$$
\frac{\mathrm{dC}_{\mathrm{DHA}}}{\mathrm{dt}}=\frac{\mathrm{k}_{\mathrm{C}} \cdot \mathrm{C}_{\mathrm{X}} \cdot \mathrm{C}_{\mathrm{G}}}{\mathrm{K}_{\mathrm{G}}+\mathrm{C}_{\mathrm{G}}}
$$


where $\mathrm{k}_{\mathrm{C}}$ is the Michaelis-Menten $(\mathrm{M}-\mathrm{M})$ kinetic constant $\left(\mathrm{L} \cdot \mathrm{gX}^{-1} \cdot \mathrm{h}^{-1}\right), \mathrm{C}_{\mathrm{G}}$ is glycerol concentration $\left(\mathrm{mol} \cdot \mathrm{L}^{-1}\right)$; and $\mathrm{K}_{\mathrm{G}}$ is the $\mathrm{M}-\mathrm{M}$ affinity constant $\left(\mathrm{mol} \cdot \mathrm{L}^{-1}\right)$.

This kinetic model assumes that the enzymes on the membrane have enough oxygen available, which is an essential co-factor for the DHA production reaction. Therefore, this kinetic model only can be applied for high stirring speeds, and will be used only in runs 16 to 18 (agitation of $400 \mathrm{rpm}$ in shake flasks) and runs 20 to 24 (stirring speed higher than $560 \mathrm{rpm}$ in STBR).

The results of the kinetic model fitting to experimental results are shown in Figure 8, and the kinetic and statistical parameters are enclosed in Table 5. As can be appreciated in Figure 8, the model is able to reproduce the experimental results very well, being able to describe the results of different runs carried out at several stirring speeds and employing different biomass concentrations in shake flasks and STBR, respectively. On the other hand, for both scales, the kinetic model satisfies statistical criteria, with very low sum of residuals (SQR), standard error of estimates (SEE), and residual mean square error (RMSE) values, while the values of VE reaches very high values (more than $98 \%$ ).
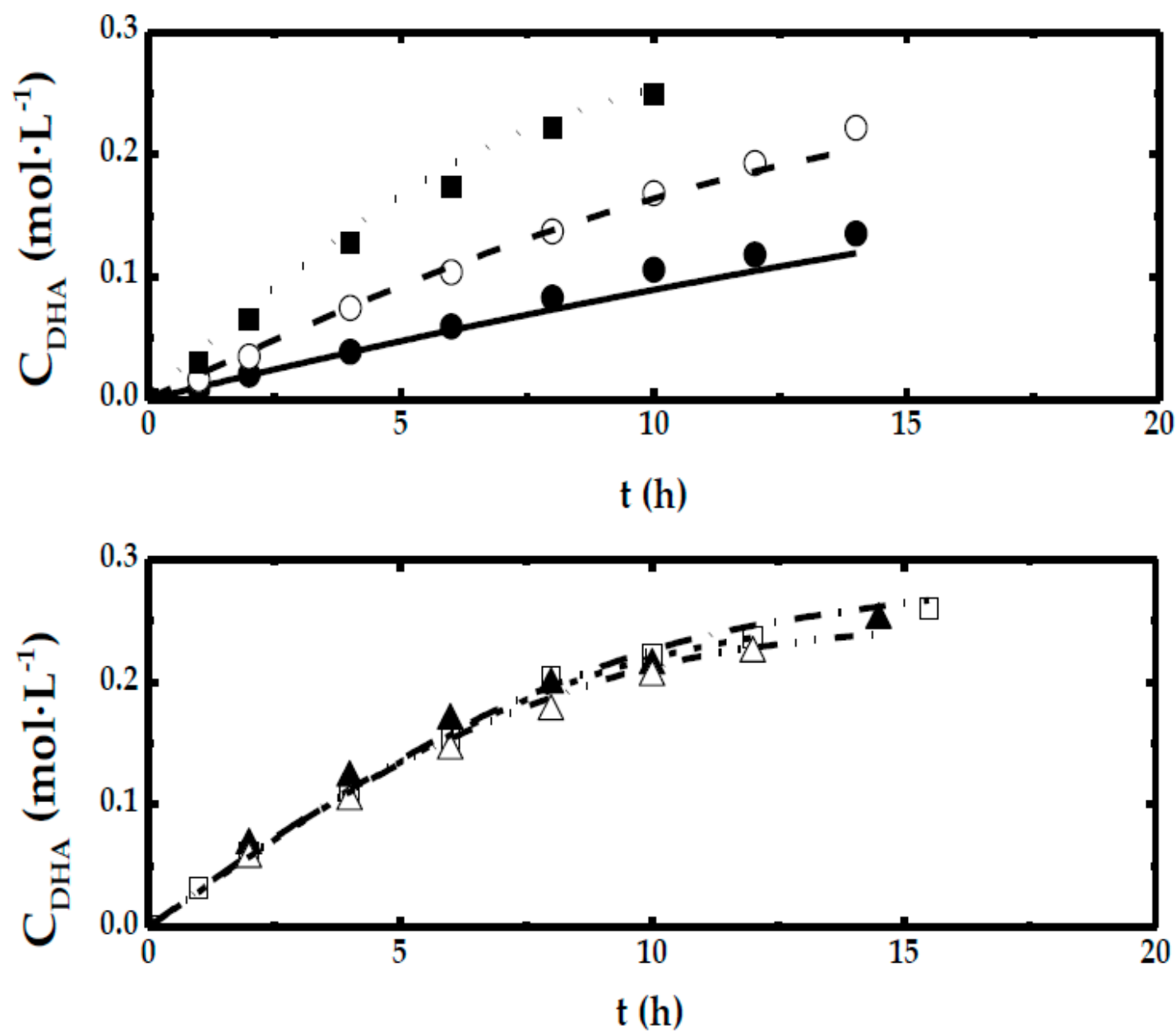

Figure 8. Reproduction of DHA concentration vs. time for runs 16 to 18 (carried out in shake flasks, (upper graphic) and for runs 22 to 24 (carried out in STBR, lower graphic). Runs in shake flasks conducted at $400 \mathrm{rpm}$ of agitation and several biomass concentrations: $0.4(\bullet), 0.5(\bigcirc)$, and $1.0 \mathrm{~g} \cdot \mathrm{L}^{-1}(\boldsymbol{\square})$. Runs carried out in STBR with a biomass concentrations of $0.5 \mathrm{~g} \cdot \mathrm{L}^{-1}$ and several stirring speeds: $560 \mathrm{rpm}(\square), 650 \mathrm{rpm}(\Delta)$, and $750 \mathrm{rpm}(\Delta)$. Points correspond to experimental results, and lines correspond to kinetic model simulation when the oxygen transport rate (OTR) is controlling the overall process rate. Model Equation (6). 
Table 5. Kinetic and statistical parameters calculated for high agitation experiments with the reaction rate control of the overall process rate. Runs 16 to 18 (shake flasks) and 22 to 24 (STBR). Model Equation (6). RMSE: residual mean square error, SQR: sum of residuals, SEE: standard error of estimates, VE: percentage of explained variance.

\begin{tabular}{ccc}
\hline Device & Parameter & Value \\
\hline & $\mathrm{k}_{\mathrm{C}}\left(\mathrm{L} \cdot \mathrm{g}_{\mathrm{x}}{ }^{-1} \cdot \mathrm{h}^{-1}\right) \cdot 10$ & $1.67 \pm 0.71$ \\
& $\mathrm{~K}_{\mathrm{G}}\left(\mathrm{mol} \cdot \mathrm{L}^{-1}\right) \cdot 10$ & $1.94 \pm 1.60$ \\
$\mathrm{SQR}$ & $1 \cdot 10^{3}$ & 2.07 \\
Shake flasks & $\mathrm{SEE}^{2} \cdot 10^{3}$ & 9.50 \\
$\mathrm{RMSE}^{3} \cdot 10^{2}$ & 4.55 \\
& $\mathrm{~F}_{\mathrm{calc}} / \mathrm{F}_{\mathrm{tab}}$ & $81.6 / 2.5$ \\
$\mathrm{VE}^{4}(\%)$ & 98.5 \\
\hline & $\mathrm{k}_{\mathrm{C}}\left(\mathrm{L} \cdot \mathrm{g}_{\mathrm{x}}{ }^{-1} \cdot \mathrm{h}^{-1}\right) \cdot 10^{2}$ & $9.50 \pm 2.49$ \\
$\mathrm{~K}_{\mathrm{G}}\left(\mathrm{mol}^{2} \mathrm{~L}^{-1}\right) \cdot 10$ & $1.55 \pm 0.82$ \\
$\mathrm{SQR}^{1} \cdot 10^{3}$ & 2.85 \\
$\mathrm{SEE}^{2} \cdot 10^{2}$ & 1.00 \\
$\mathrm{RMSE}^{3} \cdot 10^{3}$ & 9.74 \\
$\mathrm{~F}_{\mathrm{calc}} / \mathrm{F}_{\text {tab }}$ & $3990 / 2.5$ \\
$\mathrm{VE}^{4}(\%)$ & 98.7 \\
\hline & &
\end{tabular}

\subsection{Kinetic Model for Intermediate Cases: Oxygen Concentration Effect}

Although the kinetic models formulated for the previously commented fluid dynamic conditions are able to describe experiments conducted at both low and high stirring speeds, in the experimental program, there are experiments performed under intermediate conditions, and the results of these runs cannot be described using the previous kinetic models. In these experiments, the agitation and stirring speeds are neither high nor low. Consequently, in these runs, the OTR and chemical reaction rate will have a similar impact on the DHA production rate. Thus, it is necessary to propose another different kinetic model that is able to reflect the impact of oxygen availability on the DHA production rate.

For this purpose, it was mandatory to evaluate the DO concentration in the culture media during each run. Unfortunately, this was not possible for shake flasks experiments due to a lack of the required equipment. Thus, the next model was obtained only for the results corresponding to STBR experiments. The evolution of DO concentration is given in Figure 9, in which some interesting trends can be observed:

- In the run with less agitation (300 rpm), DO concentration reduces to 0 shortly after the start of the experiments. This reinforces the idea that in this case, there is a shortage in oxygen availability caused by the low mass transfer rate.

- In the experiments performed with more than $560 \mathrm{rpm}$, it can be seen that the DO concentration never reaches 0 . Therefore, it is safe to say that the OTR is far greater than the DHA production rate (chemical reaction).

- There are two runs, corresponding to those carried out at 360 and $420 \mathrm{rpm}$, in which the DO concentration reaches 0 in the first $3 \mathrm{~h}$. However, in both cases, this oxygen shortage only lasts for a short time period.

- Therefore, it is necessary to take into account the DO concentration in order to explain the DHA production rate. Thus, Equation (7) was formulated with these premises:

$$
\frac{\mathrm{d}_{\mathrm{DHA}}}{\mathrm{dt}}=\frac{\mathrm{k}_{\mathrm{C}} \cdot \mathrm{C}_{\mathrm{X}} \cdot \mathrm{C}_{\mathrm{G}}}{\mathrm{K}_{\mathrm{G}}+\mathrm{C}_{\mathrm{G}}} \cdot \mathrm{C}_{\mathrm{O} 2}^{\mathrm{n}}
$$

where $\mathrm{C}_{\mathrm{O} 2}$ is $\mathrm{DO}$ concentration $\left(\mathrm{mol} \cdot \mathrm{L}^{-1}\right)$ and $\mathrm{n}$ is an empirical exponent. 


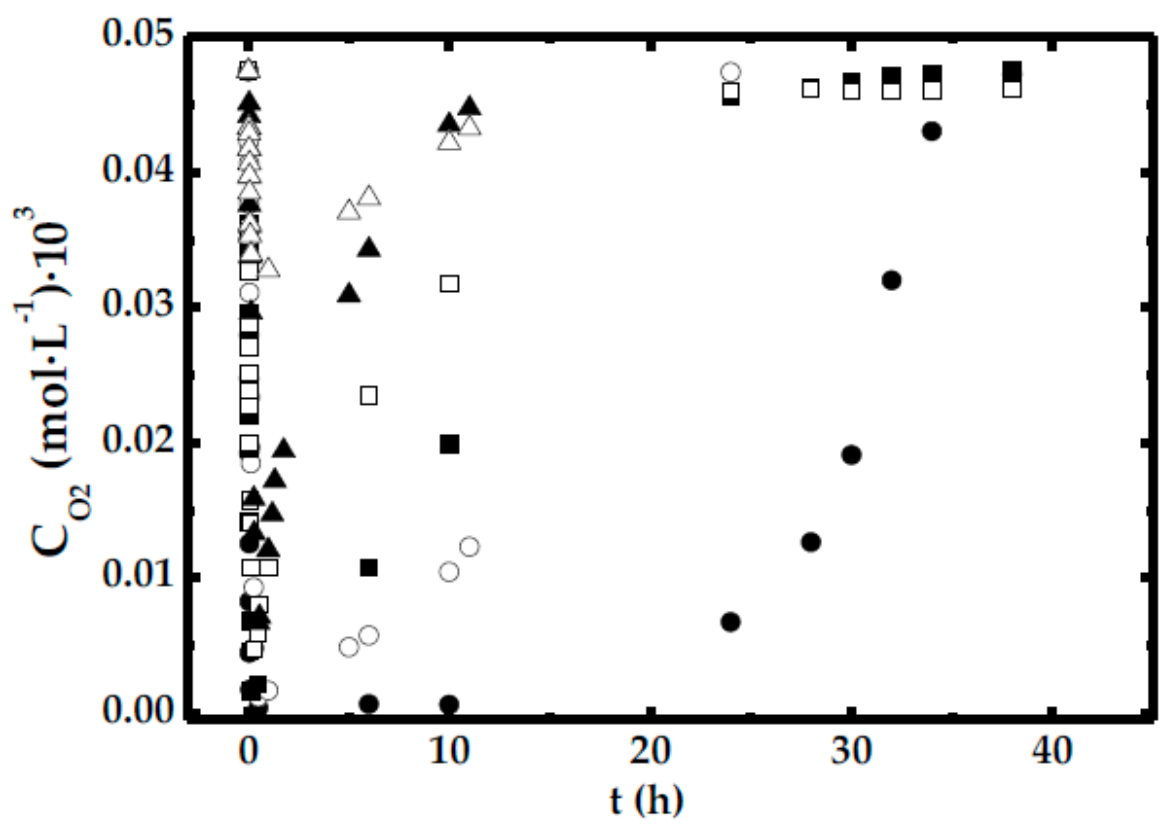

Figure 9. Experimental variation of dissolved oxygen (DO) concentration vs. time for runs 19 to 24 carried out in STBR employing different stirring speeds: $300(\bullet), 360(\bigcirc) 420(\mathbf{\bullet}), 560(\square), 650(\Delta)$, and $750 \operatorname{rpm}(\Delta)$.

The results achieved by fitting Equation (7) to the experimental results of runs 20 and 21 are shown in Figure 10, and the kinetic and statistical parameters obtained are given in Table 6.

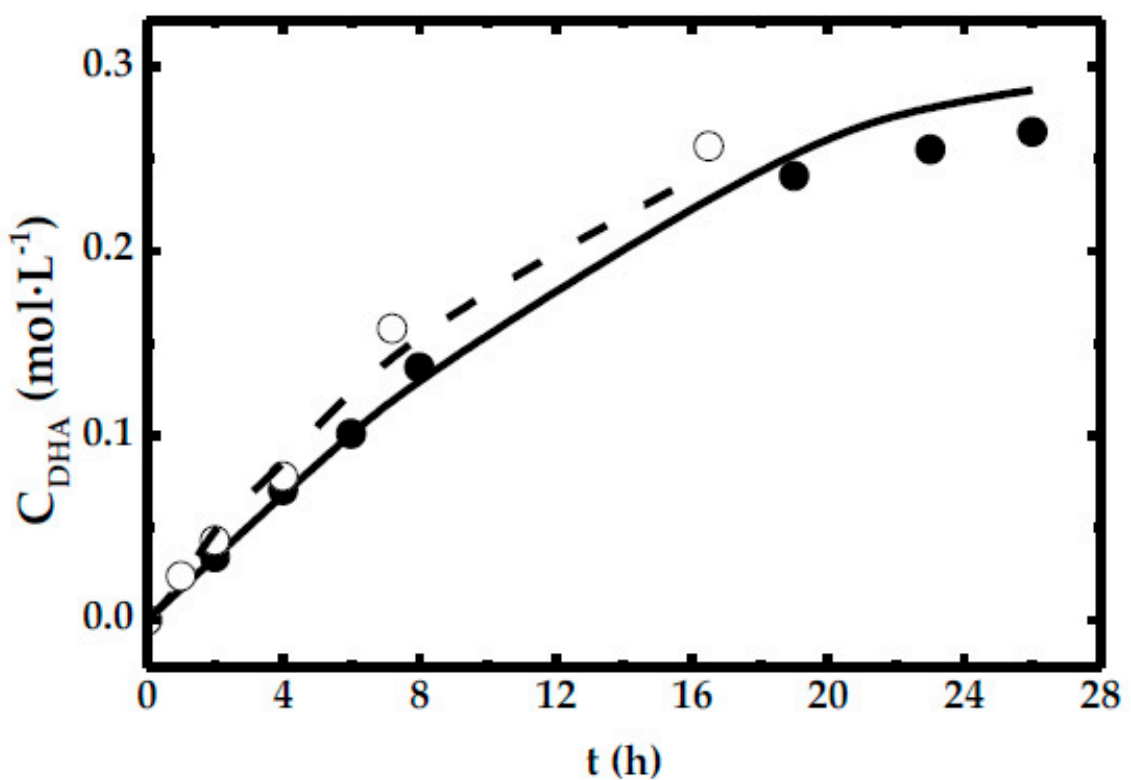

Figure 10. Variation of DHA concentration vs. time for runs 20 and 21, carried out in STBR, with stirring speeds of $360 \mathrm{rpm}(\bullet)$ and $420 \mathrm{rpm}(\bigcirc)$. Points are experimental results and lines plot the kinetic model given by Equation (7). 
Table 6. Kinetic and statistical parameters calculated for medium agitation experiments with a mix control of the mass transfer and the reaction rate. Runs 20 and 21 conducted in STBR. Model Equation (7).

\begin{tabular}{cc}
\hline Parameter & Value \\
\hline $\mathrm{k}_{\mathrm{C}}\left(\mathrm{L} \cdot \mathrm{g}_{\mathrm{x}}{ }^{-1} \cdot \mathrm{h}^{-1}\right) \cdot 10$ & $5.2 \pm 1.3$ \\
$\mathrm{~K}_{\mathrm{G}}\left(\mathrm{mol} \cdot \mathrm{L}^{-1}\right) \cdot 10$ & $5.6 \pm 2.2$ \\
$\mathrm{n}$ & $0.14 \pm 0.02$ \\
$\mathrm{SQR} \cdot 10^{3}$ & 6.26 \\
$\mathrm{SEE} \cdot 10^{2}$ & 2.40 \\
$\mathrm{RMSE} \cdot 10^{2}$ & 2.11 \\
$\mathrm{~F}_{\mathrm{calc}} / \mathrm{F}_{\mathrm{tab}}$ & $187 / 4.3$ \\
$\mathrm{VE}(\%)$ & 97.2 \\
\hline
\end{tabular}

As can be seen in Figure 10, the experimental results of both runs are perfectly described by the model shown in Equation (7). This is also reflected by the values of the kinetic and statistical parameters, which can be seen in Table 6. This result highlights even more the importance of the OTR on DHA production, especially in the cases in which the oxygen availability in the culture is not oversaturated. Furthermore, it has been demonstrated that in order to describe and to maximize the DHA production rate, it is critical to choose OTR values that meet the oxygen requirements of the enzyme to perform the glycerol transformation at the maximum reaction rate.

\section{Materials and Methods}

\subsection{Microorganism}

The strain employed in this work is Gluconobacter oxydans ATCC 621, which was provided by the Spanish Type Culture Collection (CECT 360). Bacteria were stored in a glycerol solution stock at $-80^{\circ} \mathrm{C}$. As the experiments were carried out at resting cell conditions, in which the bacteria cells are able to metabolize glycerol into DHA but can not replicate due to the lack of nitrogen source, it was necessary to grow the cells previously in two successive growth steps, employing the same methodology described in previous works [16,31].

\subsection{Experimental Procedure}

Two different experimental setups were employed in this work. In the first one, resting cells were transferred to $250 \mathrm{~mL}$ Erlenmeyer-type (shake flasks), with a working volume of $50 \mathrm{~mL}$. The medium used in these experiments contains $20 \mathrm{mM}$ of acetate buffer (initial pH of 5.5) and $25 \mathrm{~g} \cdot \mathrm{L}^{-1}$ $\left(0.27 \mathrm{~mol} \cdot \mathrm{L}^{-1}\right)$ of glycerol (supplied by Panreac AppliChem, Barcelona). The temperature was fixed at $30^{\circ} \mathrm{C}$, and the agitation was varied from 100 to $400 \mathrm{rpm}$. In the second experimental setup, a $1 \mathrm{~L}$ STBR with a working volume of $0.5 \mathrm{~L}$ was employed. The medium used in this setup was the same as the one previously described, as well as the temperature. The stirring speed was changed from 360 to $750 \mathrm{rpm}$, and the aeration was kept at $0.5 \mathrm{~L} \cdot \mathrm{min}^{-1}$ of the air flow rate. All of the experiments described in this work have been performed in triplicate, and only the mean value has been presented. The experimental error for all of the data was below $5 \%$.

\subsection{Analytical Methods}

The concentration of biomass was measured employing spectrophotometry, as the relationship between the biomass concentration and the absorbance at $600 \mathrm{~nm}$ is linear. Both the equation employed to relate the biomass concentration to the absorbance and the methodology used to this purpose were stated elsewhere $[15,16]$.

DHA, glycerol, and glyceric acid were determined by HPLC, with an Agilent 1100 series and a Rezex RHM Monosaccharide $\mathrm{H}+$ column. Temperature was maintained at $80{ }^{\circ} \mathrm{C}$, with an $0.5 \mathrm{~mL} \cdot \mathrm{min}^{-1}$ of elution rate using $1.2 \mathrm{mM} \mathrm{H} 2 \mathrm{SO} 4$ acid water dilution as the mobile phase and $15 \mu \mathrm{L}$ of injection 
volume. For DHA concentration determination, a diode array detector (DAD) was employed at $270 \mathrm{~nm}$ to measure DHA concentration, with a retention time of $16.8 \mathrm{~min}$, and a refractive index detector (RID) was employed to measure the other compounds, with a retention time of 17.6 and $15.3 \mathrm{~min}$ for glycerol and glyceraldehyde, respectively. Commercial glycerol, DHA, and glyceric acid were employed for calibration purposes (supplied by Panreac AppliChem, Barcelona).

\subsection{Mathematics and Calculations}

Productivity as a specific rate of DHA bioproduction $\left(\mathrm{P}_{\mathrm{X}}\right)$ was evaluated for each experiment employing Equation (8):

$$
P_{X}=\frac{C_{D H A}^{\max }}{C_{X} \cdot t^{\max }}
$$

where $C_{\mathrm{DHA}}^{\max }\left(\mathrm{mol} \cdot \mathrm{L}^{-1}\right)$ is the maximum DHA concentration for each experiment, and $\mathrm{t}^{\max }(\mathrm{h})$ is the time in which this concentration is reached.

To calculate $\mathrm{k}_{\mathrm{L}} \mathrm{a}$ in the runs in which the mass transfer rate exerts control over the global process rate, as well as in the applicable zones in which this control is not maintained throughout the whole reaction time, OriginLab software was employed, using a linear fitting algorithm. This software was also used for the correlation studies between $\mathrm{k}_{\mathrm{L}}$ a and stirring speed.

To fit the kinetic models to experimental data, the Aspen Custom Modeler ${ }^{\complement}$ software was employed. For the purpose of validation of the different models and in order to quantify the goodness of the fit, several statistical parameters were employed, such as the following referring to DHA concentration: Fischer's F criterion (F), sum of residuals (SQR), standard error of estimates (SEE), residual mean square error (RMSE), and percentage of explained variance (VE). All of these statistical parameters are defined in Appendix A.

\section{Conclusions}

In summary, there is an important effect of OTR on DHA production rate employing G. oxydans as the biocatalyst. For low or very low mass transfer rates, the DHA production rate is controlled by the mass transfer rate, limiting the productivity of DHA in each experiment. However, once the maximum mass transfer rate is achieved, an increase in this rate by increasing agitation does not affect the DHA production rate, which is affected by other different factors related to the chemical reaction rate, such as biomass concentration and product/substrate inhibition, as previously reported in the literature $[7,14,18,22,23]$. These achieved results are in line with the previously published results regarding this system [16].

Author Contributions: Conceptualization: V.E.S. and F.G.-O. Data curation: S.d.1.M. and M.W. Formal analysis: S.d.1.M. and M.W. Funding acquisition: V.E.S. and F.G.-O. Investigation: S.d.1.M. Methodology: S.d.1.M., M.W., V.E.S. and F.G.-O. Project administration: F.G.-O. Resources: V.E.S. and F.G.-O.; Software: S.d.1.M. and M.W.; Supervision: V.E.S. and F.G.-O. Validation: S.d.I.M. and M.W. Visualization: S.d.1.M. and M.W. Writing一original draft: M.W. Writing-review and editing: S.d.1.M., M.W., V.E.S. and F.G.-O. All authors have read and agreed to the published version of the manuscript.

Funding: This research was funded by "Ministerio de Economía, Industria y Competitividad", grant number CTQ2017-84963-C2-1-R and CTQ2010-15460 and the grant FPI BES-2011-044438.

Conflicts of Interest: The authors declare no conflict of interest.

\section{Appendix A}

Fischer's F criterion refers to the adequacy of the model to the observed values of the chosen variable, and it is based on the null hypothesis, and expressed by Equation (A1).

$$
\mathrm{F}=\frac{\sum_{\mathrm{i}=1}^{\mathrm{N}} \frac{\left(\mathrm{y}_{\mathrm{i}, \mathrm{calc}}\right)^{2}}{\mathrm{P}}}{\sum_{\mathrm{i}=1}^{\mathrm{N}} \frac{\mathrm{SQR}}{\mathrm{N}-\mathrm{P}}},
$$


where $\mathrm{y}_{\mathrm{i}}$, calc is the observed variable value predicted by the model, $\mathrm{N}$ is the number of data, $\mathrm{P}$ is the parameter number, and $\mathrm{SQR}$ is defined by Equation (A2).

$$
\mathrm{SQR}=\sum_{\mathrm{i}=1}^{\mathrm{N}}\left(\mathrm{y}_{\mathrm{i}, \exp }-\mathrm{y}_{\mathrm{i}, \text { cal }}\right)^{2},
$$

where $y_{i}, \exp$ is the experimental value for the observed variable and $y_{i}$, cal is the value predicted by the model.

SEE is calculated by Equation (A3).

$$
\mathrm{SEE}=\sqrt{\frac{\sum_{\mathrm{i}=1}^{\mathrm{N}}\left(\mathrm{y}_{\mathrm{i}, \exp }-\mathrm{y}_{\mathrm{i}, \mathrm{calc}}\right)^{2}}{\mathrm{~N}-2}},
$$

For RMSE calculation, Equation (A4) was employed.

$$
\mathrm{RMSE}=\sqrt{\frac{\mathrm{SQR}}{\mathrm{N}-\mathrm{P}}},
$$

\section{References}

1. Veluturla, S.; Archna, N.; Subba Rao, D.; Hezil, N.; Indraja, I.S.; Spoorthi, S. Catalytic valorization of raw glycerol derived from biodiesel: A review. Biofuels 2018, 9, 305-314. [CrossRef]

2. Monteiro, M.R.; Kugelmeier, C.L.; Pinheiro, R.S.; Batalha, M.O.; da Silva César, A. Glycerol from biodiesel production: Technological paths for sustainability. Renew. Sustain. Energy Rev. 2018, 88, 109-122. [CrossRef]

3. Nda-Umar, U.; Ramli, I.; Taufiq-Yap, Y.; Muhamad, E. An overview of recent research in the conversion of glycerol into biofuels, fuel additives and other bio-based chemicals. Catalysts 2019, 9, 15. [CrossRef]

4. Mitrea, L.; Trif, M.; Cătoi, A.-F.; Vodnar, D.-C. Utilization of biodiesel derived-glycerol for 1,3-PD and citric acid production. Microb. Cell Factories 2017, 16, 190. [CrossRef] [PubMed]

5. Hekmat, D.; Bauer, R.; Fricke, J. Optimization of the microbial synthesis of dihydroxyacetone from glycerol with Gluconobacter oxydans. Bioprocess Biosyst. Eng. 2003, 26, 109-116. [CrossRef] [PubMed]

6. Jain, V.K.; Tear, C.J.Y.; Lim, C.Y. Dihydroxyacetone production in an engineered Escherichia coli through expression of Corynebacterium glutamicum dihydroxyacetone phosphate dephosphorylase. Enzym. Microb. Technol. 2016, 86, 39-44. [CrossRef]

7. Lin, X.; Liu, S.; Xie, G.; Chen, J.; Li, P.; Chen, J. Enhancement of 1,3-dihydroxyacetone production from Gluconobacter oxydans by combined mutagenesis. J. Microbiol. Biotechnol. 2016, 26, 1908-1917. [CrossRef]

8. Zheng, X.J.; Jin, K.Q.; Zhang, L.; Wang, G.; Liu, Y.P. Effects of oxygen transfer coefficient on dihydroxyacetone production from crude glycerol. Braz. J. Microbiol. 2016, 47, 129-135. [CrossRef]

9. Zhou, X.; Zhou, X.; Xu, Y.; Yu, S. Improving the production yield and productivity of 1,3-dihydroxyacetone from glycerol fermentation using Gluconobacter oxydans NL71 in a compressed oxygen supply-sealed and stirred tank reactor (COS-SSTR). Bioprocess Biosyst. Eng. 2016, 39, 1315-1318. [CrossRef]

10. Hu, Z.-C.; Tian, S.-Y.; Ruan, L.-J.; Zheng, Y.-G. Repeated biotransformation of glycerol to 1,3-dihydroxyacetone by immobilized cells of Gluconobacter oxydans with glycerol- and urea-feeding strategy in a bubble column bioreactor. Bioresour. Technol. 2017, 233, 144-149. [CrossRef]

11. Poljungreed, I.; Boonyarattanakalin, S. Dihydroxyacetone production by Gluconobacter frateurii in a minimum medium using fed-batch fermentation. J. Chem. Technol. Biotechnol. 2017, 92, 2635-2641. [CrossRef]

12. Dikshit, P.K.; Moholkar, V.S. Batch and repeated-batch fermentation for 1,3-Dihydroxyacetone production from waste glycerol using free, immobilized and resting Gluconobacter oxydans cells. Waste Biomass Valorizat. 2018, 10, 2455-2465. [CrossRef]

13. Stasiak-Różańska, L.; Berthold-Pluta, A.; Dikshit, P.K. Valorization of waste glycerol to dihydroxyacetone with biocatalysts obtained from Gluconobacter oxydans. Appl. Sci. 2018, 8, 2517. [CrossRef] 
14. Sudarshan, B.; Sanjay, K. Optimization of fermentation conditions for production of 1,3-Dihydroxyacetone from glycerol obtained as a byproduct during biodiesel production. Microbiol. Res. J. Int. 2018, 1-9. [CrossRef]

15. de la Morena, S.; Acedos, M.G.; Santos, V.E.; García-Ochoa, F. Dihydroxyacetone production from glycerol using Gluconobacter oxydans: Study of medium composition and operational conditions in shaken flasks. Biotechnol. Prog. 2019, 35, e2803. [CrossRef]

16. de la Morena, S.; Santos, V.E.; García-Ochoa, F. Influence of oxygen transfer and uptake rates on dihydroxyacetone production from glycerol by Gluconobacter oxydans in resting cells operation. Biochem. Eng. J. 2019, 147, 20-28. [CrossRef]

17. Keliang, G.; Dongzhi, W. Asymmetric oxidation by Gluconobacter oxydans. Appl. Microbiol. Biotechnol. 2006, 70, 135-139. [CrossRef]

18. Deppenmeier, U.; Hoffmeister, M.; Prust, C. Biochemistry and biotechnological applications of Gluconobacter strains. Appl. Microbiol. Biotechnol. 2002, 60, 233-242.

19. Rocha-Martin, J.; Acosta, A.; Berenguer, J.; Guisan, J.M.; Lopez-Gallego, F. Selective oxidation of glycerol to 1,3-dihydroxyacetone by covalently immobilized glycerol dehydrogenases with higher stability and lower product inhibition. Bioresour. Technol. 2014, 170, 445-453. [CrossRef]

20. Xu, M.-Q.; Li, F.-L.; Yu, W.-Q.; Li, R.-F.; Zhang, Y.-W. Combined cross-linked enzyme aggregates of glycerol dehydrogenase and NADH oxidase for high efficiency in situ NAD+ regeneration. Int. J. Biol. Macromol. 2019. [CrossRef]

21. Ma, L.; Lu, W.; Xia, Z.; Wen, J. Enhancement of dihydroxyacetone production by a mutant of Gluconobacter oxydans. Biochem. Eng. J. 2010, 49, 61-67. [CrossRef]

22. Stasiak-Różańska, L.; Błażejak, S.; Gientka, I.; Bzducha-Wróbel, A.; Lipińska, E. Utilization of a waste glycerol fraction using immobilized cell extract from Gluconobacter oxydans ATCC 621 and its possible re-use. Electron. J. Biotechnol. 2017, 27, 44-48. [CrossRef]

23. Dikshit, P.K.; Moholkar, V.S. Kinetic analysis of dihydroxyacetone production from crude glycerol by immobilized cells of Gluconobacter oxydans MTCC 904. Bioresour. Technol. 2016, 216, 948-957. [CrossRef] [PubMed]

24. Dikshit, P.K.; Padhi, S.K.; Moholkar, V.S. Process optimization and analysis of product inhibition kinetics of crude glycerol fermentation for 1,3-Dihydroxyacetone production. Bioresour. Technol. 2017, 244, 362-370. [CrossRef]

25. Garcia-Ochoa, F.; Gomez, E. Bioreactor scale-up and oxygen transfer rate in microbial processes: An overview. Biotechnol. Adv. 2009, 27, 153-176. [CrossRef]

26. Rodriguez, A.; Escobar, S.; Gomez, E.; Santos, V.E.; Garcia-Ochoa, F. Behavior of several Pseudomonas putida strains growth under different agitation and oxygen supply conditions. Biotechnol. Prog. 2018, 34, 900-909. [CrossRef]

27. Acedos, M.G.; Hermida, A.; Gomez, E.; Santos, V.E.; Garcia-Ochoa, F. Effects of fluid-dynamic conditions in Shimwellia blattae (p424IbPSO) cultures in stirred tank bioreactors: Hydrodynamic stress and change of metabolic routes by oxygen availability. Biochem. Eng. J. 2019, 149, 107238. [CrossRef]

28. Garcia-Ochoa, F.; Gomez, E.; Santos, V.E.; Merchuk, J.C. Oxygen uptake rate in microbial processes: An overview. Biochem. Eng. J. 2010, 49, 289-307. [CrossRef]

29. Jackson, E.; Ripoll, M.; Betancor, L. Efficient glycerol transformation by resting Gluconobacter cells. Microbiol. Open 2019, 8, e926. [CrossRef]

30. Klöckner, W.; Büchs, J. Advances in shaking technologies. Trends Biotechnol. 2012, 30, 307-314. [CrossRef]

31. de la Torre Pascual, I.; Acedos, M.G.; Ladero, M.; Santos Mazorra, V. On the use of resting L. delbrueckii spp. delbrueckii cells for D-lactic acid production from orange peel wastes hydrolysates. Biochem. Eng. J. 2019, 145, 162-169. [CrossRef]

(C) 2020 by the authors. Licensee MDPI, Basel, Switzerland. This article is an open access article distributed under the terms and conditions of the Creative Commons Attribution (CC BY) license (http://creativecommons.org/licenses/by/4.0/). 